\title{
QUALIDADE DE LEITE UHT INTEGRAL E DESNATADO, COMERCIALIZADO NA CIDADE DE SÃO JOAQUIM DA BARRA,SP
}

\author{
LIMA, Fabiana Marquior ${ }^{1}$ \\ BRUNINI, Maria Amalia ${ }^{2}$ \\ MACIEL JÚNIOR, Vinicius Antonio ${ }^{3}$ \\ MORANDIN, Carla de Souza ${ }^{1}$ \\ RIBEIRO, Carolina Thomazini ${ }^{1}$
}

Recebido em: 2009-03-26

Aprovado em: 2009-04-29

Issue DOI: $10.3738 / 1982.2278 .187$

RESUMO: O objetivo deste trabalho foi o de analisar algumas características físico-químicas do leite UHT (ultra pasteurização) integral e desnatado, comercializado na cidade de São Joaquim da Barra/SP e comparar os resultados com os padrões da legislação vigente. Foram analisadas 4 marcas de leite integral e 4 marcas de leite desnatado, quanto a acidez, $\mathrm{pH}$, sólidos solúveis totais, umidade, densidade e teor de proteína.. Os resultados obtidos permitem concluir que quanto aos teores de proteína, $\mathrm{pH}$ e sólidos solúveis do leite UHT integral e leite UHT desnatado, os mesmo atendem aos padrões citados na literatura para o leite, mas com relação aos valores encontrados para a acidez, com exceção do leite integral da marca $C$, pode-se concluir que as marcas de leite analisadas estão em desacordo com o padrão estabelecido pela legislação vigente. No geral, pode-se concluir que há necessidade de novos estudos, tendo em vista que o leite é um alimento essencial para o ser humano e animal.

Palavras-chave: Leite UHT integral. Leite UHT desnatado. Acidez. pH. Proteína do leite.

\section{QUALITY OF UHT INTEGRAL AND UHT SHIMMILK COMMERCIALIZED IN THE SÃO JOAQUIM DA BARRA CITY, SP, BRAZIL}

SUMMARY: The aim of this work was to analyse same physical and chemical characteristics of milk UHT integral and UHT shimmilk commercialized in the San Joaquim da Barra/SP, situated in the San Paulo state, and to compare the results with the present legislation. Its was analysed 4 UHT milk integral type and 4 UHT milk shimtype about acidity, $\mathrm{pH}$, soluble solids, moisture content, desinty and protein teor is fer. The results shower that about the protein teor, soluble solids and pH of UHT milk attended the standards in the literature for milk, but with respect to the values of acidity with the exception the $\mathrm{C}$, it may be concluded that the brands of milk aren't adequate for consumption because they are in disagreement with the standards cited in the literature. In general it was concluded that there is need for further studies in view that milk is an essential food for humans and animal.

Keywords: UHT milk integral. UHT milk shim. Acidity. pH. Milk protein. \begin{tabular}{l}
\hline 1 Acadêmica do Curso de Ciências Biológicas da Faculdade de Filosofia, Ciências e Letras de Ituverava, Fundação \\
Educacional de Ituverava. Rua Coronel Flauzino Barbosa Sandoval, 1259, Ituverava, SP, Brasil, CEP=14500-000. \\
$2 \quad$ Professora Adjunto Aposentada da Faculdade de Ciências Agrárias e Veterinárias/UNESP, Campus de Jaboticabal e \\
Professora Doutora da Faculdade Dr. Francisco Maeda -FAFRAM/ Fundação Educacional de Ituverava. Rua Coronel Flauzi- \\
no Barbosa Sandoval, 1259, Ituverava, SP, Brasil, CEP=14500-000. \\
$3 \quad$ Engenheiro Agrônomo. Professor Mestre da Faculdade Dr. Francisco Maeda- FAFRAM/ Fundação Educacional de \\
Ituverava. Rua Coronel Flauzino Barbosa Sandoval, 1259, Ituverava, SP, Brasil, CEP=14500-000.
\end{tabular} 


\section{INTRODUÇÃO}

Dentre os alimentos considerados de alto valor biológico, o leite ocupa um lugar de destaque, por sua riqueza em constituintes nutritivos e energéticos, em estado facilmente assimilável, torna-o recomendável para a dieta humana, além de ser o alimento mais indicado no combate à subnutrição proteica de lactentes (LEITE JR. et al., 2000; FERREIRA, 1977). Segundo Prata (1998) é considerado o mais completo alimento, devido a sua rica composição em proteína, gordura, carboidratos, sais minerais e vitaminas.

O leite por ser um dos alimentos mais completos em termos nutricionais, sua qualidade é uma preocupação constante para técnicos e autoridades ligados à área da saúde e zootécnica. (TIMM et al., 2003; LEITE JR. et al., 2000; KANESIRO et al., 1977). Segundo Polegato e Rudge (2003) as maiores preocupações quanto a qualidade físico-químico do leite estão associadas ao estado de conservação, tratamento térmico e a sua integridade física e química, principalmente as relacionados a adição ou remoção de substâncias químicas próprias ou adição de substâncias estranhas a sua composição.

A qualidade do leite é avaliada, principalmente pela acidez, a qual tem seus limites de tolerância fixada por leis (KANESIRO et al., 1977), e a determinação da mesma vem sendo bastante utilizada em indústrias lácteas e pesquisadores devido a facilidade e rapidez de análise. A acidez do leite pode aumentar através da hidrólise da lactose, por enzimas microbianas que levam a formação de acido lático, e se a acidez for muito alta, o leite é considerado impróprio para o consumo, pois indica atividade microbiana (OLIVEIRA; NUNES, 2003). A acidez do leite, também, pode diminuir devido à ação do tratamento térmico, e esta diminuição é que leva o leite a coagulação (PRATA, 1998; FRANCO; LANDGRAF, 1996).

A densidade tem importância tecnológica, quando se pretende calcular o peso do leite requerido, quando se investiga uma possível adulteração no leite e na hora de normalizar automaticamente o teor de gordura (SPRESER, 1991), e de acordo com Luquet (1991), a densidade pode servir de base para uma detecção sumária e bastante rápida de fraude por adição de água. Segundo Polegato e Rudge (2003), valores de densidade abaixo de 1,028 pode indicar a adição de água e acima de 1,034 adição de outras substâncias ou desnate do leite.

Pela legislação brasileira, leite normal é um produto que apresenta teor de gordura de no mínimo 3\%, acidez em graus Dornic entre 15 e 20, densidade a $15^{\circ} \mathrm{C}$ entre 1,028 a 1,034, teor de lactose no mínimo de $4,3 \%$, extrato seco desengordurado de no mínimo $8,4 \%$, extrato seco total de no mínimo 11,5\%, entre outros caracteres (BRASIL, 2002).

A atual tendência do mercado em produzir produtos de qualidade, com longa vida de prateleira e praticidade ao consumidor, gerou o interesse de inúmeros laticínios em produzir o leite UHT. Segundo Alves (2001) e Meirelles (2000), este tipo de produto mostrou-se ser bastante adequado as condições brasileiras, uma vez que sua comercialização não requer sistemas de distribuição refrigerada. Normalmente, o leite UHT consegue atingir uma durabilidade de até seis meses, porém sofre algumas alterações com o decorrer do tempo, devido à atuação 
das enzimas termo resistentes produzidas pelas bactérias psicrotróficas, pois este processo, de ultra pasteurização não esteriliza completamente o leite (ARCURI et al., 2006; MARTINS et al., 1999).

Segundo o Regulamento Técnico de Identidade e Qualidade de Produtos Lácteos do Ministério da Agricultura, Pecuária e Abastecimento (BRASIL, 1997), o leite UHT deve atender as seguintes características sensoriais: aspecto líquido, cor branca, odor e sabor característicos, sem sabores nem odores estranhos e as seguintes características físico-químico para o leite integral: no mínimo 3\% de gordura, acidez entre 14 e $18^{\circ}$ Dormic, estabilidade ao álcool de $68 \%$ e, no mínimo $8,2 \%$ de desengordurado.

Santos et al. (2007) analisando lotes de leite UHT, em relação aos aspectos físicoquímicos, microbiológicos e sensoriais, durante sua vida de prateleira, evidenciaram que a qualidade desse tipo de leite é a principal causa da deterioração com o decorrer do tempo de armazenamento, e que a partir do segundo mês de fabricação, o leite UHT começa a apresentar pequenas, porém visíveis, modificações, como geleificação no fundo da caixinha, coloração não homogênea, sabor e odor indesejáveis e diminuição no teor de gordura.

Tendo em vista o apresentado, idealizou-se o presente trabalho com o objetivo de analisar algumas características físico-químicas de leite UHT, integral e desnatado, comercializado na cidade de São Joaquim da Barra/SP, bem como a comparação dos resultados obtidos com os padrões da legislação vigente.

\section{METODOLOGIA}

As marcas de leite UHT (ultra pasteurização) integrais e desnatados utilizadas neste trabalho foram adquiridas através de seleção aleatória em supermercados da cidade de São Joaquim da Barra/SP, no mês de agosto de 2008. Foram analisadas 4 marcas de leite integral, aqui denominadas de A, B, E e C e 4 de leite desnatado, aqui denominadas de A, B, D e C, que, imediatamente, após obtenção, foram conduzidas até o Laboratório de Ciências de Alimentos da Faculdade Dr. Francisco Maeda, Ituverava/SP, para análise dos parâmetros: pH, acidez, umidade, teor de proteína, sólidos solúveis totais e densidade.

A acidez foi determinada por método titulométrico, utilizando solução de $\mathrm{NaOH} \mathrm{N} / 9$ (Solução de Dornic) e os resultados expressos em gramas de ácido lático por $100 \mathrm{~mL}$, (AOAC, 1997) e em 'Dornic; o pH através do uso de potenciômetro digital, da marca MA 200 (AOAC, 1997); os teores de sólidos solúveis totais foram determinados por reflatometria, utilizandose refratômetro Palette (PR-201) da Atago, e os resultados expressos em \% (AOAC, 1997); a umidade determinada por secagem em estufa de secagem e renovação de ar, até peso constante e os resultados expressos em porcentagem (AOAC, 1997); a densidade determinada através de termolacto densímetro com correção de temperatura a 15 (PENNA et al., 2001); e o teor de proteína, determinado através do método de Kjeldahl que se baseia na transformação do azato 
orgânico, geralmente encontrado sobre a forma de amina ou amida, em sulfato de amônio, estável e fixo, e o valor de $\mathrm{N}$ obtido foi multiplicado por 6,98 (CIÊNCIA E INOVAÇÂO, 1997).

As marcas de leite foram avaliadas segundo o delineamento experimental inteiramente casualizado, composto por 4 tratamentos e 5 repetições. Os dados obtidos foram submetidos à análise de variância, comparando-se as médias obtidas através do teste de Tukey, ao nível $5 \%$ de probabilidade (BANZATTO e KRONKA 1995), utilizando-se programa computacional ESTAT da Faculdade de Ciências Agrárias e Veterinárias, Campus de Jaboticabal / UNESP.

\section{RESULTADOS E DISCUSSÃO}

Na Tabela 1 estão apresentados as médias e a análise estatística dos resultados de $\mathrm{pH}$, acidez e sólidos solúveis totais, onde pode-se observar que ocorreu variações em função do tipo e marca de leite UHT. Os valores de pH variam de 6,62 a 6,72 e 6,59 a 6,69, respectivamente, em leite UHT integral e leite UHT desnatado e estão dentro do limite citado por Oliveira (2005) para o leite normal que é de 6,6 a 6,75 .

A acidez do leite expressa em graus Dornic $\left({ }^{\circ} \mathrm{D}\right)$, variou de $20,15^{\circ} \mathrm{D}$ a $18,68^{\circ} \mathrm{D}$ em leite integral e de $20,31^{\circ} \mathrm{D}$ a $21,28^{\circ} \mathrm{D}$ em leite desnatado. Estes dados mostram que os leite analisados, independente do tipo e da marca, com exceção do leite integral da marca $C$, estão fora do padrão exigido pela legislação, pois segundo o Regulamento Técnico de Identidade e Qualidade de Produtos Lácteos do Ministério da Agricultura, Pecuária e Abastecimento, a acidez do leite UHT deve estar entre 14 e $18^{\circ} \mathrm{D}$ (BRASIL 1997).

TABELA 1: $\mathrm{pH}$, acidez e sólidos solúveis totais (\%) em leite UHT integral e desnatado. (Média de 5 repetições).

\begin{tabular}{|c|c|c|c|c|}
\hline \multirow[t]{3}{*}{ Amostras de Leite } & \multirow[t]{3}{*}{$\mathrm{pH}$} & \multicolumn{2}{|c|}{ Acidez } & \multirow{3}{*}{$\begin{array}{l}\text { Sólidos Solúveis Totais } \\
\left({ }^{\circ} \text { Brix }\right)\end{array}$} \\
\hline & & ${ }^{\circ}$ Dornic & g. de ácido & \\
\hline & & & lático/100 mL & \\
\hline \multicolumn{5}{|c|}{$\begin{array}{l}\text { lático/100 mL } \\
\text { Leite Integral }\end{array}$} \\
\hline A & $6,62 \mathrm{c}$ & $20,15 \mathrm{a}$ & $0,201 \mathrm{a}$ & $12,56 \mathrm{c}$ \\
\hline B & $6,72 \mathrm{a}$ & $18,68 b$ & $0,186 \mathrm{~b}$ & $12,36 \mathrm{c}$ \\
\hline $\mathrm{E}$ & $6,67 b$ & $19,82 \mathrm{a}$ & $0,198 \mathrm{a}$ & $13,64 a$ \\
\hline $\mathrm{C}$ & $6,62 \mathrm{c}$ & $20,31 \mathrm{a}$ & $0,203 a$ & $12,80 \mathrm{~b}$ \\
\hline $\mathrm{dms}^{(1)}$ & 0,0177 & 0,7403 & 0,0748 & 0,2200 \\
\hline $\mathrm{S}^{(1)}$ & 0,0097 & 0,4088 & 0,0413 & 0,1214 \\
\hline c.v. $(\%)^{(1)}$ & 0,15 & 2,07 & 0,209 & 0,95 \\
\hline$F^{(1)}$ & $122,58 * *$ & $16,20 * *$ & $16,94 * *$ & $107,39 * *$ \\
\hline \multicolumn{5}{|c|}{ Leite Desnatado } \\
\hline $\mathrm{A}$ & $6,64 b$ & $20,47 a b$ & $0,205 \mathrm{ab}$ & $10,28 b$ \\
\hline B & $6,62 b c$ & $20,31 b$ & $0,203 b$ & $10,64 a$ \\
\hline $\mathrm{D}$ & $6,69 a$ & $20,31 b$ & $0,203 b$ & $10,14 b$ \\
\hline $\mathrm{C}$ & $6,59 \mathrm{c}$ & $21,28 \mathrm{a}$ & $0,213 \mathrm{a}$ & $10,32 b$ \\
\hline $\mathrm{dms}^{(1)}$ & 0,288 & 0,8718 & 0,0857 & 0,2309 \\
\hline $\mathrm{S}^{(1)}$ & 0,0159 & 0,4813 & 0,0473 & 0,1275 \\
\hline c.v. $(\%)^{(1)}$ & 0,24 & 2,34 & 0,230 & 1,23 \\
\hline$F^{(1)}$ & $34,40 * *$ & $4,69 *$ & $4,71 *$ & $13,73 * *$ \\
\hline
\end{tabular}

${ }^{(1)} \mathrm{dms}=$ diferença mínima significativa para comparação das medias pelo teste de Tukey; ${ }^{(2)} \mathrm{s}=$ desvio padrão das medias; ${ }^{(1)} \mathrm{F}=$ *significativo a $5 \%$ de nível de probabilidade; **significativos a $1 \%$ de nível de probabilidade; ns= não significativos; ${ }^{(1)}$ c.v. $=$ coeficiente de variação em porcentagem; m.g. = média geral. 
Quanto aos teores de ácido lático, pelos dados apresentados na Tabela 1, pode-se verificar que os valores variaram de $0,186 \mathrm{~g}$ a $0,205 \mathrm{~g}$ por $100 \mathrm{ml}$, valores estes que estão acima do limite citado na Portaria Nº146 de 7 de Março de 1996 do Ministério da Agricultura e do Abastecimento e da Reforma Agrária (Brasil,2005).

Estes resultados obtidos para acidez indicam que pode ter ocorrido falta de higiene durante a produção, pois segundo Oliveira e Nunes (2003) acidez elevada no leite pode ser atribuída a acidificação da lactose provocada pela multiplicação de microorganismo.

Sólidos solúveis totais são representados pelos ácidos, sais, vitaminas, aminoácidos, algumas proteínas e açúcares, entretanto, a fração de açúcar é maior que a dos outros atributos, o que na prática, consideram-se sólidos solúveis totais como açúcar (KANESIRO et al., 1977), e neste estudo, através dos dados obtidos, que estão apresentados na Tabela 1, pode-se verificar que os teores de sólidos solúveis totais tiveram pouca variação e que os leite integrais são os que apresentam os maiores teores.

Com relação a densidade os valores obtidos (dados não mostrados) mostraram que não houve diferença entre os leites analisados. Para o leite UHT desnatado a densidade foi 1,025 e para o integral foi 1,026. Os valores obtidos neste estudo estão dentro do limite citado pela RIISPOA (1977) para o leite in natura que é de 1,028 a 1,030g/ml. Estes resultados obtidos, para densidade, mostram que os leites UHT analisados não sofreram nenhum tipo de fraude, quer seja pela adição de água ou adição de remoção de substâncias, segundo a citação de Polegado e Rudge (2003).

O teor de água do leite UHT desnatado e integral estão apresentados na Figura 1, onde se pode verificar que os maiores valores foram encontrados no leite de marca C. Os valores aqui obtidos são coerentes ao encontrado para a densidade, pois mostram que não ocorreu a adição de água durante a fabricação e estão de acordo com dados da literatura.

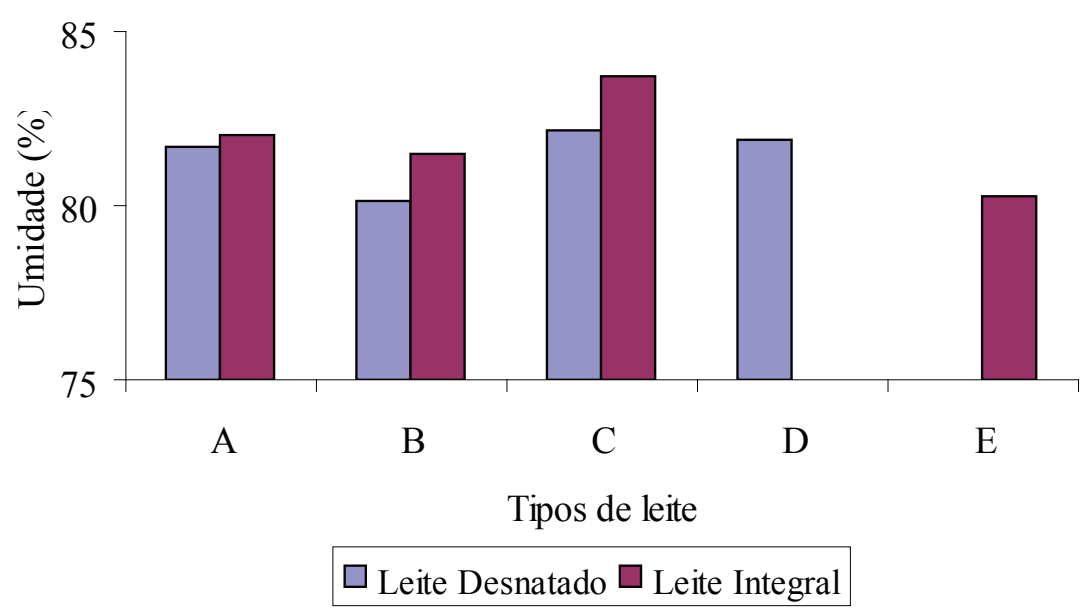

FIGURA 1: Teor de umidade, expresso em porcentagem, em leite UHT integral e desnatado. A proteína do leite tem alto valor biológico, ou seja, é completa e de excelente qualidade, com valor variando de 3,3 a 3,5\% (SGARBIERI, 2005). Neste estudo, os teores de proteínas encontrados variaram de 3,90 a 5,02 g por $100 \mathrm{~mL}$ no leite UHT integral e de 4,47 a 5,16 g por 
100 mL no leite UHT desnatado (Figura 2).

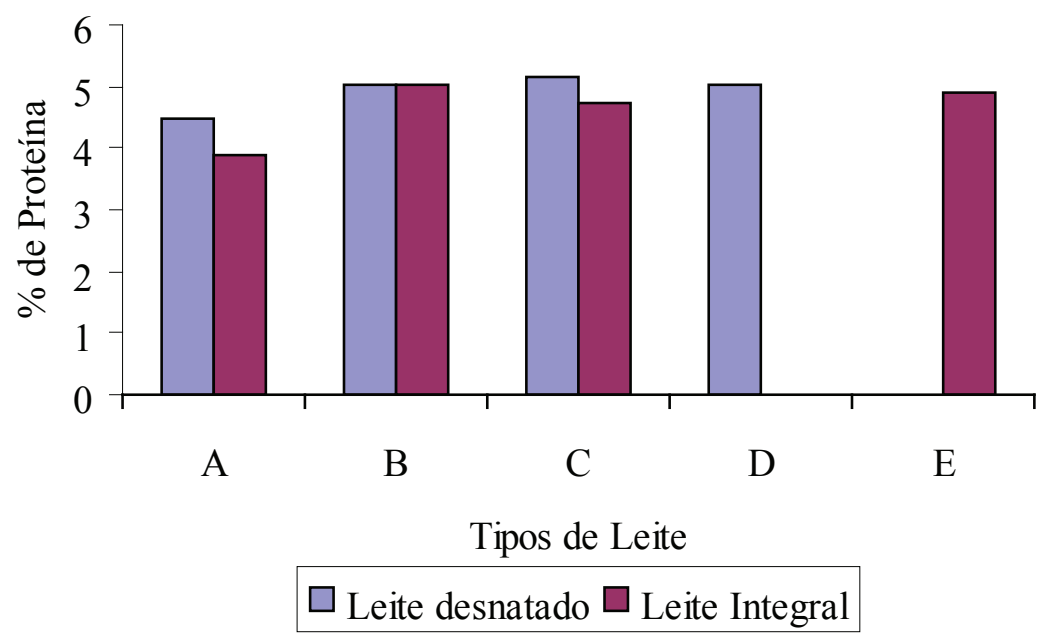

FIGURA 2: Teor de proteína, expresso em porcentagem, em leite UHT desnatado e integral.

Os valores obtidos neste estudo (Figura 2) estão acima dos valores citados para o leite 'in natura' por Sgarbieri (2005) que é de 3,3 a 3,5\%. Também, os valores aqui obtidos são superiores aos encontrados por Sousa et al. (2004) em leite UHT provenientes de dois laticínios da região norte e noroeste do estado do Paraná, que é de 3,16 e 3,23.

Os valores médios obtidos, neste estudo, para os leites UHT integral e leite UHT desnatados analisados, foram superiores aos valores obtidos no leite por Jensen (1995).

$\mathrm{O}$ alto valor de proteína obtido nas amostras avalizadas indicam que o processo de ultra pasteurização, a que os leites foram submetidos, não desnaturaram a proteína do leite, e que estas marcas de leite são boa fonte de proteína, independente que seja leite UHT desnatado ou leite UHT integral, parâmetros importante em termos de saúde e qualidade de vida.

\section{CONCLUSÃO}

Os resultados obtidos permitem concluir que, com relação aos teores de proteína, $\mathrm{pH}$ e sólido solúveis do leite UHT integral e leite UHT desnatado, esses leites atendem aos padrões citados na literatura para o leite, mas com relação aos valores encontrados para a acidez, com exceção do leite integral da marca $\mathrm{C}$, pode-se concluir que as marcas de leite analisadas estão em desacordo com o padrão estabelecido pela legislação vigente. No geral, pode-se concluir que há necessidade de novos estudos, tendo em vista que o leite é um alimento essencial para o ser humano e animal. 


\section{REFERÊNCIAS}

AOAC - ASSOCIATION OF OFFICIAL ANALYSTICAL CHEMISTS. Official methods of analysis. Edited by Patricia Cunniff. 16 ed. 3 rd, v.2, cap. 37. 1997.

ALVES, Daniela R. The Role of UHT milk in the Growth of the Brazilian Milk Market. The Australian Journal of Dairy Technology, Australia, vol. 56, n.2, p.116, july 2001.

ARCURI, E. F. et al. Qualidade microbiológica do leite refrigerado nas fazendas. Arq. Bras. Med. Vet. Zootec, v. 58, n. 3, p. 440-446, 2006.

BASTOS, M. S. R. Leite longa vida UHT: Aspectos do processamento e identificação dos pontos críticos de controle. Revista Higiene Alimentar, São Paulo, v. 13, n. 66/67, p. 32-36, 1999.

BRASIL, P. A. Eficiência da contagem microscópica na avaliação da qualidade pregressa da matéria-prima utilizada no processamento de leite UAT*. (*ultra alta temperatura). Jaboticabal, 2002, 53 f. Dissertação (Mestre em Medicina Veterinária Preventiva), Faculdade de Ciências Agrárias e Veterinárias, Universidade Estadual Paulista (UNESP).

BRASIL, Ministério de agricultura, Pecuária e Abastecimento Secretaria de Defesa Agropecuária. Instruções Normativas no 51 de 18 de Setembro de 2002. Diário Oficial da União, 20 set.2002.

CIÊNCIA E INOVAÇÃO 2010 - PROGRAMA OPERACIONAL CIÊNCIA E INOVAÇÃO 2010. Disponível em: <http://www.poci2010.mctes.pt/home>. Acesso em: 03 novembro de 2008 .

FERREIRA, A.C. A importância do leite e seus produtos. Indústria Alimentar, São Paulo, v.8, p.46-50, mar./abr. 1977.

FRANCO, B. D. G. M.; LANDGRAF, M. Microbiologia dos alimentos. São Paulo: Atheneu, 1996. p. 155-164.

JENSEN, R. G. Handbook of milk composition. San Diego: Academic Press, 1995.

KANESIRO, M. A. B. Variação do grau de acidez e densidade em leite pasteurizado tipo "C", fervido ou não, quando armazenado à temperatura de $7^{\circ} \mathrm{C}$. Científica, Jaboticabal, v. 5, n. 2, p. 236-240, 1977. 
LEITE JR., A. F. S.; TORRANO, A. D. M.; GELLI D.S. Qualidade Microbiológica do leite C pasteurizado, comercializado em João Pessoa, Paraíba. Revista Higiene Alimentar, São Paulo, v.14, n.74, p.45-49, 2000.

LUQUET, F. M. Leche y productos lácteos. Acribia: Zaragoza, 1991. 390p.

MARTINS, R. S; SANTOS, C. V. ; TEIXEIRA,S.R. Alterações da rede logística e expansão do mercado de leite longa vida no Brasil. Organização rurais e agroindustriais, Lavras,v.1, n.2, p.55-69,1999,

MEIRELES, A. J. A DesRazão laticinista a indústria de laticínios no último quartel do século XX. São Paulo: Cultura Editores Associados , 1986. 268p.

OLIVEIRA, A. B. Características de composição do leite e métodos de análise. In: CURSO SOBRE QUALIDADE DO LEITE, 2, 16f. 2005. Goiânia: Escola Veterinária/Universidade de Goiás. Goiânia, 2005. (Mimeografada).

OLIVEIRA, M. M. A.; NUNES, I. F. Análise Microbiológico e físico-químico do leite pasteurizado "tipo C" comercializado em Teresina, PI. Revista Higiene Alimentar, São Paulo, v.17, n.111, p.92-94, 2003.

PENNA, C. F. de. A. M. Determinação da densidade do leite. Belo Horizonte: Departamento de Tecnologia e Inspeção de Produtos de Origem Animal,2001.p.9(apostila).

PRATA, L. F. Leite UHT: solução ou problema? Uma análise da situação. Revista Higiene Alimentar, São Paulo, v. 12, n. 54, p. 10-15, 1998.

PRATA, L. F.et al. Composição perfil nitrogenado e características do leite caprino (Saanen). Região Sudeste, Brasil. Ciência e Tecnologia de Alimentos. v. 18, n. 4, Campinas, Oct./Dec. 1998.

PINTO, C. L. O.; MARTINS, M. L.; VANETTI, M. C. D. Qualidade microbiológica de leites crus refrigerados e isolamento de bactérias psicrotróficas proteolíticas. Ciência e Tecnologia de Alimentos, Campinas, v. 26, n. 3, p. 645-651, jul./set. 2006.

POLEGATO, E.P. S.; RUDGE,A.C. Estudos das características físico-químico e microbiológicos dos leites produzidos por mini-usinas da região de Marilia - São Paulo / Brasil. Revista Higiene Alimentar, São Paulo, v.17, n.110, p.56-63, 2003.

Nucleus Animalium, v.1, n.1, maio 2009 
RIISPOA - REGULAMENTO DA INSPEÇÃO INDUSTRIAL E SANITÁRIA DE PRODUTOS DE ORIGEMANIMAL. Disponível em: < http://www.scribd.com/doc/3194328/ RIISPOA>. Acesso em: 30 out. 2008.

SANTOS, M. G. O. de et al. Pesquisa de microrganismos mesófilos baseado no sistema de análises de perigo e pontos críticos de controle-APPCC em seis mini usinas de leite de cabra do Cariri paraibano. Revista do Instituto de Laticínios Cândido Tostes. Juiz de Fora. v.60, n.345, p.276-279, jul/ago de 2005.

SGARBIERI, V. C. Revisão: Propriedades estruturais e físico - químicos das proteínas do leite. Braz. J. Food Technnol, Campinas, v.8, n.1, p.43-56, jan./mar.2005.

SOUSA, L. G. de. Avaliação da composição do leite UHT proveniente de dois laticínios das regiões Norte e Noroeste do Estado do Paraná. Acta Scientium Animal Science, Maringá, v.26, n.2, p.259-264, 2004.

SPRESER, E. Lactologia Industrial. 2 ed. Zaragoza: Acribia, 1991. p.51.

TIMM, C.D. et al. Avaliação da qualidade microbiológica do leite pasteurizado integral, producido em micro-usinas da região Sul do Rio Grande do Sul. Revista Higiene Alimentar, São Paulo, v.17, n.106, p.100-104, 2003. 